\title{
Factors affecting the duration of coronary artery lesions in patients with the Kawasaki disease: a retrospective cohort study
}

\author{
Xuting Zhang ${ }^{\dagger}$, Yuee He ${ }^{\dagger}$, Yiping Shao, Biyao Hang, Zhipeng Xu and Maoping Chu* (D)
}

\begin{abstract}
Background: Coronary artery lesions (CALs) are the most severe complication of Kawasaki disease (KD). Approximately 9-20\% of the patients with KD develop CAL despite receiving regular treatment (intravenous immunoglobulin [IVIG] and aspirin). Some patients develop coronary aneurysms, leading to coronary artery stenosis or thrombosis, resulting in ischaemic heart disease and significantly affect the patients' lives. The purpose of this study was to investigate the factors associated with the duration of CAL in patients with KD.

Methods: The data of 464 patients with KD and CAL admitted to the Children's Heart Centre, The Second Affiliated Hospital and Yuying Children's Hospital from 2010 to 2018 were retrospectively analysed. Demographic and clinical information and echocardiographic follow-up data were collected. Kaplan-Meier curves were used to estimate the overall CAL duration, and the log-rank test was used to compare statistical differences. Univariate and multivariate Cox regression models were used to identify variables related to the CAL duration.
\end{abstract}

Results: The median CAL duration was 46 days (95\% confidence interval: 41-54 days). CALs were observed in 61.5, $41.5,33.3,22.3,10.3$, and $7.7 \%$ of the patients at 1 month, 2 months, 3 months, 6 months, 1 year, and 2 years after the onset of KD, respectively. Univariate Cox regression model showed that sex $(p=0.016)$, rash symptoms ( $p=$ 0.035), delayed IVIG treatment ( $p=0.022)$, CAL type $(p<0.001)$, degree of CAL $(p<0.001)$, white blood cell count before IVIG treatment $(p=0.019)$, and platelet count after IVIG treatment $(p=0.003)$ were statistically significant factors associated with the overall CAL duration. Multivariable Cox regression showed that delayed IVIG treatment $(p=0.020)$, multiple dilatations ( $p<0.001)$, a greater degree of dilatation $(p<0.001)$, and higher platelet count after IVIG treatment $(p=0.007)$ were positively related to CAL duration.

Conclusions: CAL duration was affected by delayed IVIG treatment, type of CAL, degree of CAL, and platelet count after IVIG treatment. These factors should be monitored carefully during the follow-up and management of patients with $\mathrm{KD}$ and $\mathrm{CAL}$.

Keywords: Kawasaki disease, Mucocutaneous lymph node syndrome, Prognosis, Survival analysis, Coronary artery lesions, Kaplan-Meier curve, Multivariate cox regression model

\footnotetext{
* Correspondence: chmping@hotmail.com

${ }^{+}$Xuting Zhang and Yuee He contributed equally to this work.

Children's Heart Center, The Second Affiliated Hospital and Yuying Children's Hospital, Institute of Cardiovascular Development and Translational Medicine, Wenzhou Medical University, Wenzhou, 325000 Zhejiang, China
}

(c) The Author(s). 2021 Open Access This article is licensed under a Creative Commons Attribution 4.0 International License, which permits use, sharing, adaptation, distribution and reproduction in any medium or format, as long as you give appropriate credit to the original author(s) and the source, provide a link to the Creative Commons licence, and indicate if changes were made. The images or other third party material in this article are included in the article's Creative Commons licence, unless indicated otherwise in a credit line to the material. If material is not included in the article's Creative Commons licence and your intended use is not permitted by statutory regulation or exceeds the permitted use, you will need to obtain permission directly from the copyright holder. To view a copy of this licence, visit http://creativecommons.org/licenses/by/4.0/ The Creative Commons Public Domain Dedication waiver (http://creativecommons.org/publicdomain/zero/1.0/) applies to the data made available in this article, unless otherwise stated in a credit line to the data. 


\section{Background}

Kawasaki disease (KD) is an acute febrile vasculitis of unknown aetiology that predominantly affects children aged $<5$ years. Its pathological features include systemic inflammation of medium-sized blood vessels and various tissues and organs. The coronary arteries are typically the most affected vessels [1, 2]. Although KD is generally considered self-limiting and treated with high-dose intravenous immunoglobulin (IVIG), 9-20\% of the patients with KD develop coronary artery lesions (CALs) and 4\% develop coronary artery aneurysms (CAAs) [3$6]$.

Persistent CALs may lead to thrombosis, stenosis, and obstruction, causing major adverse cardiac events, such as unstable angina pectoris and myocardial infarction, and even death $[7,8]$. One study reported that $5 \%$ of the acute coronary syndromes in patients aged $<40$ years with suspected myocardial ischaemia were related to CAA secondary to KD [9]. Several previous studies have reported that patients with more severe CAL, especially those with aneurysms, tend to have a longer CAL duration and a greater risk of developing coronary events later in life $[10,11]$. Thus, several guidelines for patients with CAL recommend follow-up plans according to the degree of CAL $[1,2]$.

Recently, paediatricians have focused on patients with KD and CAA [12-16]. However, patients with coronary artery dilation, but not CAA, comprise the majority of the patients with CAL $[3,5]$. Although coronary artery dilation in most patients normalizes within 2 months after its onset, CAL persists or progresses in some patients $[1,2,11]$. Considering the large number of patients affected by KD worldwide, these patients cannot be ignored. In addition to the degree of CAL, previous studies have reported several other factors related to the prognosis of patients with $\mathrm{KD}$ with $\mathrm{CAL}$; however, no consensus has been achieved regarding these factors $[10$, $11,17,18]$. Therefore, we conducted a retrospective cohort study to determine the prognosis of all patients with KD with CAL and determine the relationship between factors, such as laboratory data, treatment plans, IVIG resistance, and CAL duration.

\section{Methods}

\section{Patients}

We collected the demographic and clinical information of 511 patients with KD and CAL admitted to the Children's Heart Centre of The Second Affiliated Hospital and Yuying Children's Hospital from 1 January 2010 to 31 December 2018. KD diagnosis was based on the 2017 American Heart Association (AHA) guidelines and CAL diagnosis was based on the expert consensus in this region. Due to missing clinical information, 47 patients were excluded; therefore, 464 patients were included in the final analysis. Patients were divided into two groups based on the degree of CAL (patients with multiple CALs were grouped according CAL severity): the dilation group (absolute diameter of the coronary artery $<4$ $\mathrm{mm}$ ) and the aneurysm group (absolute diameter of the coronary artery $\geq 4 \mathrm{~mm}$ ) (Fig. 1).

\section{Data collection}

The patients' medical data and follow-up records, including the patients' age, weight, sex, KD type, clinical symptoms, IVIG resistance, delayed IVIG treatment, CAL type, and degree of CAL, were collected from the electronic medical record system of the hospital. Laboratory data including the white blood cell, neutrophil, and platelet counts $\left(10^{9} / \mathrm{L}\right)$; haematocrit $(\%)$; erythrocyte sedimentation rate $(\mathrm{mm} / \mathrm{h})$; and haemoglobin $(\mathrm{g} / \mathrm{L}), \mathrm{C}$ reactive protein $(\mathrm{mg} / \mathrm{L})$, alanine aminotransferase and aspartate aminotransferase $(\mathrm{U} / \mathrm{L})$, albumin $(\mathrm{g} / \mathrm{L})$, sodium $(\mathrm{mmol} / \mathrm{L})$, potassium $(\mathrm{mmol} / \mathrm{L})$, chloride $(\mathrm{mmol} / \mathrm{L})$, and brain natriuretic peptide $(\mathrm{pg} / \mathrm{mL})$ levels were recorded before and after IVIG treatment.

Patients underwent two or three echocardiography during their hospitalization, often with an interval of 45 days. The follow-up echocardiography was conducted once every 2 weeks within 6 months after discharge and once every 1-2 months in the later period. Every echocardiography was performed by at least two experienced paediatric echocardiographers. For the echocardiographic follow-up of the same patient, our heart centre used the same echocardiographers as much as possible. The absolute dimensions of the left main coronary artery (LMCA), left anterior descending artery (LAD), left circumflex (LCX), right coronary artery (RCA), and posterior descending coronary artery (PDCA) were recorded each time. This study's primary endpoint was the overall duration of CAL, defined as the duration between the first date of CAL detection on echocardiography and the date of its disappearance on echocardiography. The disappearance of CAL in echocardiography was defined as normalization of absolute inner diameter, which means the absolute inner diameter is smaller than the diagnostic criteria.

\section{Diagnosis of KD}

According to the 2017 AHA guidelines, the clinical criteria for the diagnosis of KD include a prolonged, unexplained fever lasting for $\geq 5$ days and the presence of four or more of the five major clinical symptoms, namely bilateral conjunctival congestion, polymorphous rash, oral changes, acute non-purulent cervical lymphadenopathy, and extremity changes [1].

A patient with unexplained fever for $>5$ days, $<4$ of the major clinical symptoms, and supportive laboratory 


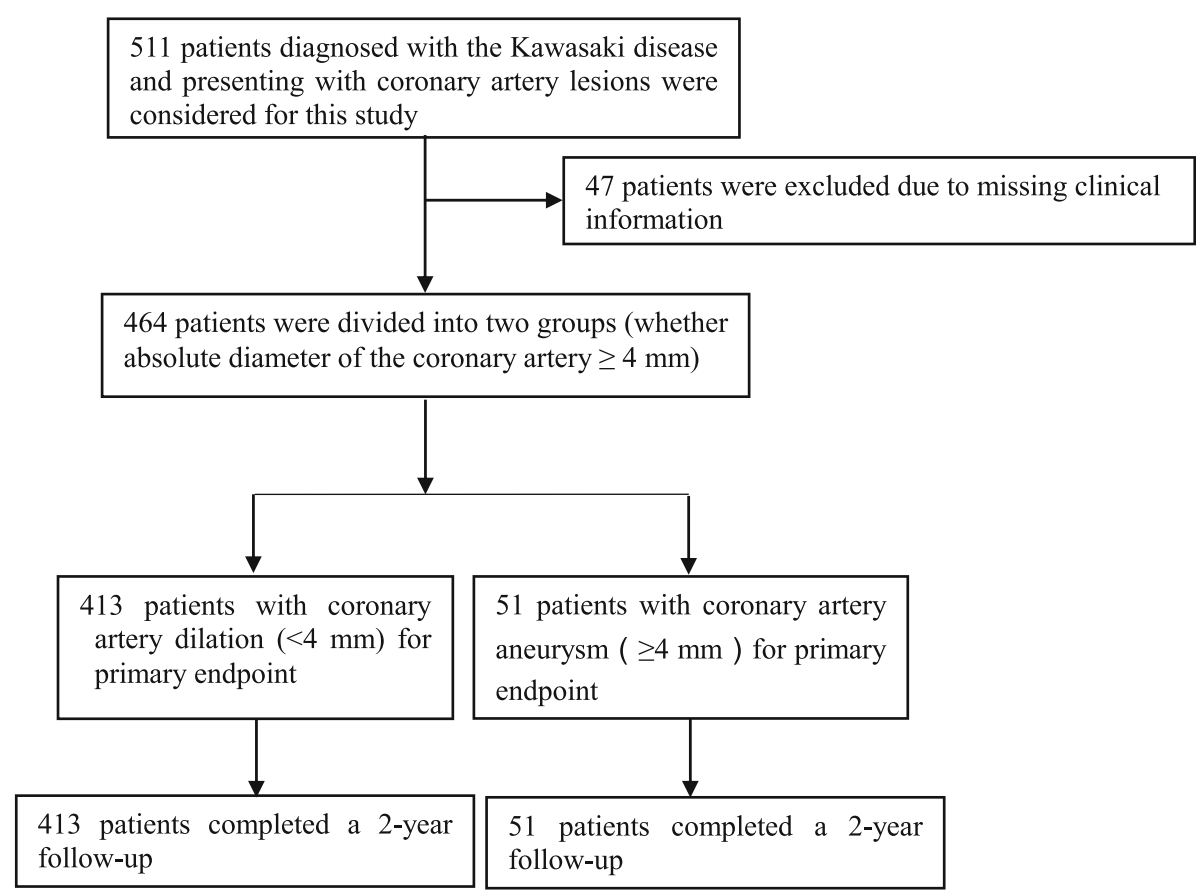

Fig. 1 Patient flow chart. Flow chart showing the demographic and clinical information of all study participants. A total of 47 patients were excluded; 464 patients were included in the final analysis. The patients were divided into two groups based on the degree of coronary artery lesions

findings or coronary artery abnormalities was considered to have incomplete (or atypical) KD [1].

IVIG resistance was defined as a body temperature of $>38.5^{\circ} \mathrm{C}$ at $48 \mathrm{~h}$ after the end of IVIG infusion [19]. Delayed IVIG treatment was defined as the administration of IVIG > 10 days after disease onset $[1,2]$.

CALs were classified according to their size as follows: absolute coronary artery diameter $>2.5 \mathrm{~mm}$ for children aged $<3$ years, $>3 \mathrm{~mm}$ in children aged $3-9$ years, and $>$ $3.5 \mathrm{~mm}$ in children aged $>9$ years. CAAs were diagnosed if the absolute diameter of the coronary artery was $\geq 4$ $\mathrm{mm}$. The range of small, medium, and giant CAAs was defined by a diameter $<5,5-8$, and $>8 \mathrm{~mm}$, respectively [20]. Single CAL was defined as CAL in one of the following arteries: LMCA LAD, LCX, RCA, or PDCA. Multiple CAL was defined as CAL in more than one of these arteries.

\section{Statistical methods}

Continuous variables are expressed as means \pm standard deviation or interquartile range, and categorical variables are summarised as numbers and percentages. Continuous and categorical variables were compared among the groups using the $t$ - or the Mann-Whitney's $U$ tests (as appropriate) and the Pearson's Chi-square or the Fisher's exact tests (as appropriate), respectively. The overall duration of CAL was estimated using the Kaplan-Meier curve method, and the log-rank test was used to compare the variables. A univariate Cox analysis was conducted to explore the variables associated with the overall duration of CAL. Statistically significant variables in the univariate Cox regression analysis were included in the multivariate Cox model. Statistical significance was set at $p<0.05$. All statistical analyses were performed using the R software (version 3.6.1, R Foundation for Statistical Computing, Vienna, Austria). The Cox regression analyses were performed using the 'survival' package and the Kaplan-Meier curves were created using the R package 'ggplot2'.

\section{Results}

Demographic and clinical characteristics

Of the 464 patients with KD included in this study, 411 and 53 were categorised into the dilation and aneurysm groups, respectively. Patients in the aneurysm group were significantly older $(p<0.001)$ and heavier $(p=$ 0.002 ) than those in the dilation group (Table 1). The proportions of patients with rash $(p=0.007)$ and oral symptoms $(p=0.025)$ in the aneurysm group were lower than those in the dilation group. A higher proportion of patients in the aneurysm group received delayed IVIG treatment $(p=0.018)$. In addition, more patients in the aneurysm group had multiple CALs $(p<0.001)$ than the dilation group. There were no significant differences in the sex, KD type, other clinical symptoms, or IVIG resistance between the two groups (Table 1). 
Table 1 Patient characteristics

\begin{tabular}{|c|c|c|c|}
\hline & $\begin{array}{l}\text { Dilation group } \\
N=413(89.0 \%)\end{array}$ & $\begin{array}{l}\text { Aneurysm group } \\
N=51(11.0 \%)\end{array}$ & $\begin{array}{l}P \\
\text { value }\end{array}$ \\
\hline Age (months) & $18.3(10.6-28.4)$ & $35.7(15.1-63.8)$ & $<0.001^{*}$ \\
\hline Weight (kg) & $11.0(9.4-13.0)$ & $14.0(11.0-20.0)$ & $0.002^{*}$ \\
\hline $\operatorname{Sex}(M / F)$ & $308 / 105$ & $43 / 8$ & 0.175 \\
\hline KD type & & & 0.799 \\
\hline Complete & $321(77.7 \%)$ & $41(80.4 \%)$ & \\
\hline Incomplete & $92(22.3 \%)$ & $10(19.6 \%)$ & \\
\hline \multicolumn{4}{|l|}{ Symptoms } \\
\hline Fever & 410 (99.3\%) & $51(100 \%)$ & 0.999 \\
\hline LN enlargement & $181(43.8 \%)$ & $22(43.1 \%)$ & 0.999 \\
\hline Rash & $312(75.5 \%)$ & $29(56.9 \%)$ & $0.007^{*}$ \\
\hline Conjunctivitis & 377 (91.3\%) & 48 (94.1\%) & 0.674 \\
\hline Oral changes & $366(88.6 \%)$ & $39(76.5 \%)$ & $0.025^{*}$ \\
\hline Extremity changes & $287(69.5 \%)$ & $32(62.7 \%)$ & 0.412 \\
\hline Delayed IVIG treatment & $45(10.9 \%)$ & $12(23.5 \%)$ & $0.018^{*}$ \\
\hline IVIG-resistant & $32(7.7 \%)$ & $7(13.7 \%)$ & 0.236 \\
\hline CAL types & & & $<0.001^{*}$ \\
\hline Single & $327(79.2 \%)$ & $15(29.4 \%)$ & \\
\hline Multiple & $86(20.8 \%)$ & $36(70.6 \%)$ & \\
\hline
\end{tabular}

Continuous data are shown as median (interquartile range). Categorical data are shown as number (percentage)

Abbreviations: $C A L$ coronary artery lesion; $M$ male; $F$ female; $K D$ Kawasaki disease; IVIG intravenous immunoglobulin; $L N$ lymph node

Delayed IVIG was defined as the administration of IVIG > 10 days after disease onset

Single CAL was defined as CAL in one of the following arteries: LMCA LAD, LCX, RCA, or PDCA.. Multiple CAL was defined as CAL in more than one of these arteries
The neutrophil count was higher $(p=0.027)$, and the aspartate aminotransferase level was lower in the aneurysm group $(p=0.029)$ than in the dilation group before IVIG treatment. There were no significant differences in the laboratory data after IVIG treatment between the two groups. The detailed demographic and clinical characteristics are presented in Tables 2 and 3.

\section{Kaplan-Meier curve and cox proportional hazards regression analyses}

The median CAL duration was 46 days (95\% confidence interval [CI]: 41-54 days). CALs were observed in 61.5, $41.5,33.3,22.3,10.3$, and $7.7 \%$ of the patients at 1 month, 2 months, 3 months, 6 months, 1 year, and 2 years after disease onset, respectively (Fig. 2A). The median CAL duration in the dilation and aneurysm groups was 41 days (95\% CI: 35-46 days) and 265 days (95\% CI: 152-720 days), respectively (Fig. 2B). As shown in Fig. 3, the CAL duration was prolonged once the $\mathrm{KD}$ patients developed CAA.

The results of the univariate Cox regression analysis revealed that the CAL type (single vs. multiple) $(\mathrm{p}<$ $0.001)$, delayed IVIG treatment $(p=0.003)$, sex $(p=$ $0.016)$, and rash symptoms $(p=0.035)$ were correlated with the CAL duration (Fig. 3A-D). The degree of CAL $(\mathrm{p}<0.001$, Fig. $2 \mathrm{~B})$, white blood cell count before IVIG therapy $(p=0.019)$, and platelet count after IVIG therapy $(\mathrm{p}=0.003)$ were also associated with the CAL duration (Table 4). Delayed IVIG treatment (hazard ratio [HR]: 0.722; 95\% CI: 0.550-0.950; $p=0.020)$, multiple dilations (HR: 0.516; 95\% CI: 0.392-0.677; $p<0.001$ ), greater dilation (HR: 0.319; 95\% CI: $0.202-0.505 ; p<$ 0.001 ), and increased platelet count after IVIG (HR:

Table 2 Laboratory data before the initiation of IVIG treatment

\begin{tabular}{llll}
\hline & Dilation group $(\boldsymbol{N}=\mathbf{4 1 3})$ & Aneurysm group $(\boldsymbol{N}=\mathbf{5 1})$ & $P$ value \\
\hline White blood count $\left(10^{9} / \mathrm{L}\right)$ & $15.3(11.8-19.3)$ & $16.6(13.0-21.0)$ & 0.281 \\
Haemoglobin $(\mathrm{g} / \mathrm{L})$ & $110.3 \pm 10.9$ & $111.4 \pm 10.1$ & 0.482 \\
Haematocrit $(\%)$ & $0.33(0.32-0.36)$ & $0.33(0.31-0.36)$ & 0.365 \\
Platelet count $\left(10^{9} / \mathrm{L}\right)$ & $393.7 \pm 159.7$ & $411.9 \pm 159.9$ & 0.447 \\
Neutrophil count $\left(10^{9} / \mathrm{L}\right)$ & $10.4 \pm 5.2$ & $12.0 \pm 4.9$ & $0.027^{*}$ \\
C-reactive protein $(\mathrm{mg} / \mathrm{L})$ & $76.0(43.0-119.0)$ & $88.0(51.9-136.0)$ & 0.141 \\
Erythrocyte sedimentation rate $(\mathrm{mm} / \mathrm{h})$ & $35.2 \pm 13.9$ & $37.5 \pm 12.9$ & 0.235 \\
Alanine aminotransferase $(\mathrm{U} / \mathrm{L})$ & $39.0(20.0-93.0)$ & $35.0(18.5-65.0)$ & 0.064 \\
Aspartate aminotransferase $(\mathrm{U} / \mathrm{L})$ & $33.0(25.0-52.0)$ & $27.0(23.0-43.5)$ & $0.029^{*}$ \\
Albumin $(\mathrm{g} / \mathrm{L})$ & $36.9 \pm 5.8$ & $35.6 \pm 5.2$ & 0.107 \\
Sodium $(\mathrm{mmol} / \mathrm{L})$ & $135.7 \pm 2.5$ & $135.8 \pm 2.4$ & 0.728 \\
Potassium $(\mathrm{mmol} / \mathrm{L})$ & $4.37 \pm 0.53$ & $4.23 \pm 0.57$ & 0.098 \\
Chloride $(\mathrm{mmol} / \mathrm{L})$ & $101.7 \pm 3.1$ & $101.0 \pm 2.9$ & 0.125 \\
Brain natriuretic peptide $(\mathrm{pg} / \mathrm{mL})$ & $887(395-2213)$ & $656(195.5-1865)$ & 0.539 \\
\hline
\end{tabular}

Data are shown as mean \pm standard deviation or median (interquartile range) Abbreviation: IVIG intravenous immunoglobulin 
Table 3 Laboratory data after IVIG treatment

\begin{tabular}{llll}
\hline & Dilation group $(\boldsymbol{N}=\mathbf{4 1 3})$ & Aneurysm group $(\boldsymbol{N}=\mathbf{5 1})$ & $\boldsymbol{P}$ value \\
\hline White blood count $\left(10^{9} / \mathrm{L}\right)$ & $8.4(6.6-10.6)$ & $8.0(5.4-10.9)$ & 0.741 \\
Haemoglobin $(\mathrm{g} / \mathrm{L})$ & $107.3 \pm 10.9$ & $109.3 \pm 11.9$ & 0.258 \\
Haematocrit $(\%)$ & $0.33(0.31-0.35)$ & $0.33(0.31-0.35)$ & 0.474 \\
Platelet count $\left(10^{9} / \mathrm{L}\right)$ & $555.0 \pm 189.7$ & $517.1 \pm 173.5$ & 0.150 \\
Neutrophil count $\left(10^{9} / \mathrm{L}\right)$ & $3.3 \pm 2.3$ & $4.7 \pm 6.5$ & 0.132 \\
C-reactive protein $(\mathrm{mg} / \mathrm{L})$ & $8.7(5.0-16.0)$ & $8.0(4.0-17.4)$ & 0.364 \\
Alanine aminotransferase $(\mathrm{U} / \mathrm{L})$ & $29.0(20.0-48.0)$ & $34.0(23.5-505.5)$ & 0.730 \\
Aspartate aminotransferase $(\mathrm{U} / \mathrm{L})$ & $46.0(38.0-61.0)$ & $45.0(37.5-66.5)$ & 0.418 \\
Albumin $(\mathrm{g} / \mathrm{L})$ & $35.6 \pm 4.0$ & $34.9 \pm 5.2$ & 0.338 \\
Brain natriuretic peptide $(\mathrm{pg} / \mathrm{mL})$ & $231(159-336)$ & $278(201-441)$ & 0.143
\end{tabular}

Data are shown as mean \pm standard deviation or median (interquartile range)

Abbreviation: IVIG intravenous immunoglobulin

0.999; 95\% CI: $0.9986-0.9998 ; p=0.007)$ were found to be independently associated with the CAL duration (Table 4).

\section{Discussion}

To our knowledge, the present investigation is one of the largest studies to focus on the prognosis of patients with KD and CAL and explore the risk factors associated with CAL duration. Over the two-year follow-up, the CALs resolved in 312/464 patients, and the median regression time was 46.0 days. The regression rate of $67.2 \%$ in this study is lower than that reported in previous studies [10, 11, 21].

We found that the degree of CAL was associated with the prognosis, which is consistent with the previously reported findings. Miura et al. reported that the greater the coronary dilation, the higher the probability of future adverse cardiovascular events [7]. Other studies have reported that small and medium CAAs resolve more frequently than giant CAAs, which is consistent with our findings $[11,14,22]$. KD can lead to severe coronary artery damage. We found that the duration of CALs in children with multiple CALs was longer than that in children with a single CAL. The severity of CAL reflects the extent of inflammation. The following three linked KD vasculopathy process primarily involve muscular arteries: necrotising arteritis, subacute/chronic vasculitis, and luminal myofibroblastic proliferation (LMP) [1] Orenstein et al. reported that subacute/chronic vasculitis may occur or persist for several months or years and that LMP causes progressive coronary arterial stenosis and thrombosis [8], which occur more frequently in patients with CAA.
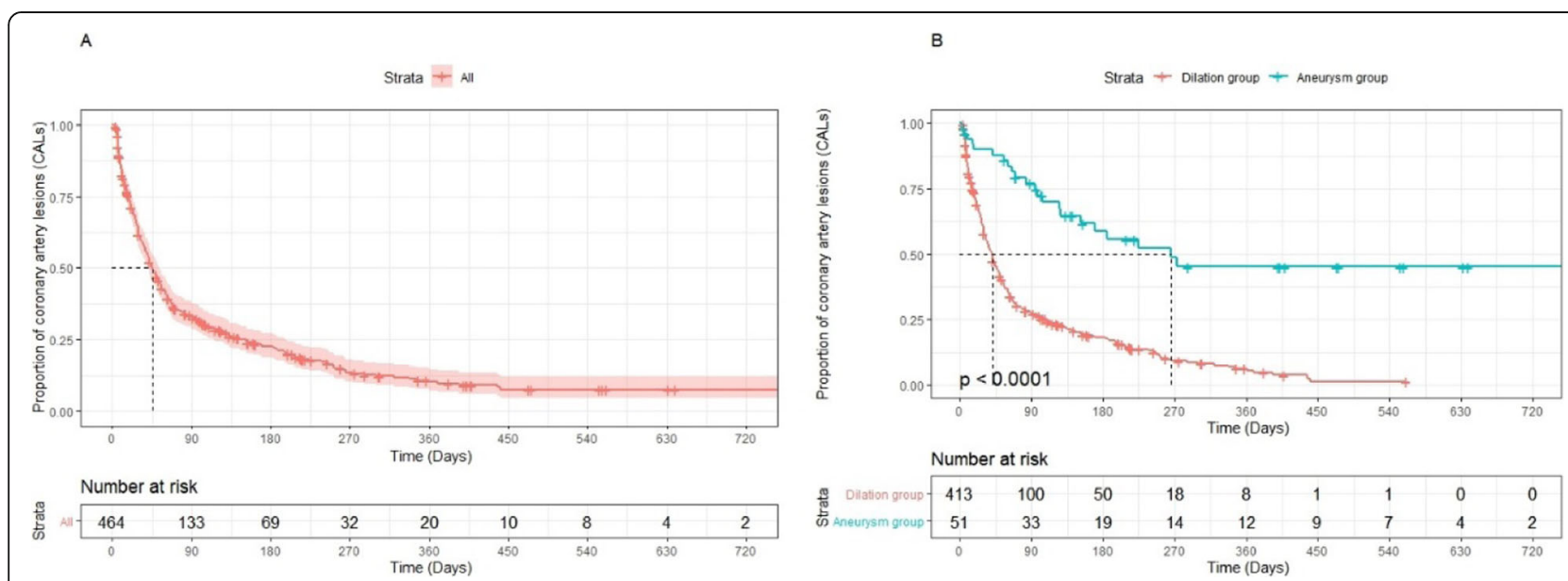

Fig. 2 Kaplan-Meier curves for coronary artery lesion duration. A. The duration of coronary artery lesions (CALs) for all patients is shown. The median CAL duration was 46 days (95\% confidence interval [CI]: 41-54 days). B. The durations of coronary artery lesions for patients with dilation (absolute diameter of coronary artery $<4 \mathrm{~mm}$ ) and aneurysm (absolute diameter of coronary artery $\geq 4 \mathrm{~mm}$ ) are shown. The CAL duration was prolonged once the KD patients developed CAA (41 days vs. 265 days) 


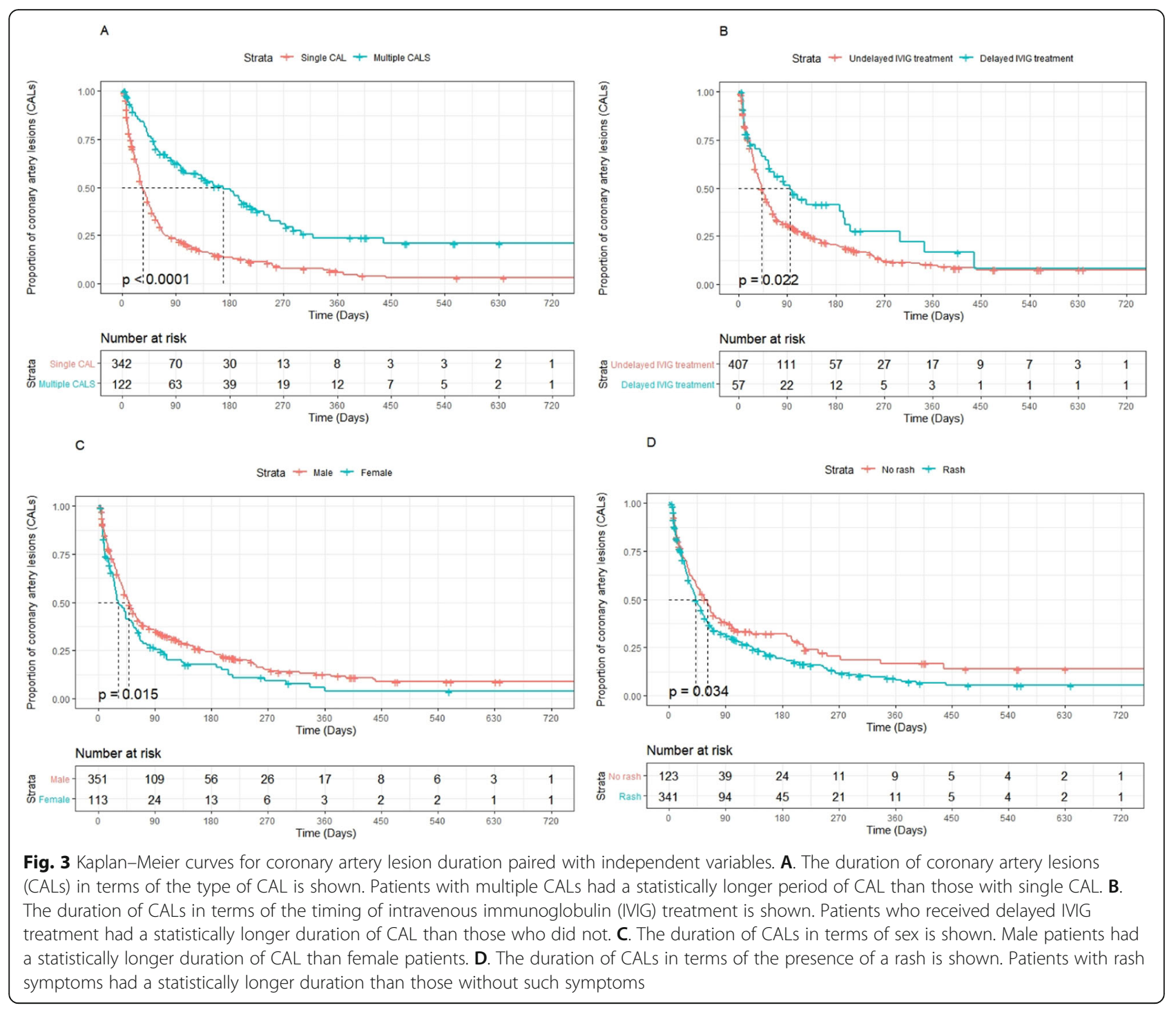

Paediatricians often monitor the platelet count in patients with KD. In Japan, the platelet count is used to predict IVIG-resistant coronary aneurysms [23, 24]. The natural trend of the platelet count in patients with KD can be divided into three different stages. First, the platelet count is normal, and no platelet aggregation is seen. Then, the platelets are activated, and the platelet count increases. This typically occurs as fever improves, and the rash begins to scale, often in the second or third week of the disease. The changes at this stage are due to the release of serotonin from the platelets. Finally, the platelet count returns within the normal range; however, children with coronary aneurysms continue to be at a risk of elevated platelet counts [25, 26]. Therefore, during the early stage of $\mathrm{KD}$, the platelet count decreases before it increases slowly. Patients with higher platelet counts $\left(>450 \times 10^{9} / \mathrm{L}\right)$ are more likely to develop CAA and not respond to IVIG than patients with normal platelet counts $\left(150-450 \times 10^{9} / \mathrm{L}\right)$ [25]. In our study, the platelet count measured before IVIG treatment initiation was lower in the aneurysm group than in the dilation group. The platelet count measured after IVIG treatment was higher in the aneurysm group than in the dilation group, although these differences were not significant. We found that the longer the duration of coronary artery dilation, the higher the platelet count after IVIG, which is consistent with previous studies.

According to several guidelines, the optimal time for administering IVIG is $5-10$ days after the onset of illness $[1,2]$. The late onset of typical symptoms in some patients with KD or difficulty in referring patients to specialists may delay the IVIG treatment. Previous studies $[27,28]$ have reported that delayed IVIG treatment may lead to an increased risk of CAL and longer CAL durations in patients with $\mathrm{KD}$, which are consistent with our results. 
Table 4 Factors associated with CAL duration

\begin{tabular}{|c|c|c|c|c|}
\hline & \multicolumn{2}{|l|}{ Univariate } & \multicolumn{2}{|l|}{ Multivariate } \\
\hline & $\mathrm{HR}(95 \% \mathrm{Cl})$ & $P$ value & $\mathrm{HR}(95 \% \mathrm{Cl})$ & $P$ value \\
\hline \multicolumn{5}{|l|}{ Sex } \\
\hline Male & Reference & 1.00 & Reference & 1.00 \\
\hline Female & $1.334(1.055-1.686)$ & $0.016^{*}$ & $1.215(0.958-1.540)$ & 0.108 \\
\hline \multicolumn{5}{|l|}{ Rash } \\
\hline Yes & Reference & 1.00 & Reference & 1.00 \\
\hline No & 1.295 (1.019-1.645) & $0.035^{*}$ & $0.976(0.761-1.251)$ & 0.846 \\
\hline \multicolumn{5}{|l|}{ IVIG treatment } \\
\hline Not delayed & Reference & 1.00 & Reference & 1.00 \\
\hline Delayed & $0.672(0.515-0.875)$ & $0.022^{*}$ & $0.722(0.550-0.950)$ & $0.020^{*}$ \\
\hline \multicolumn{5}{|l|}{ CAL type } \\
\hline Single & Reference & 1.00 & Reference & 1.00 \\
\hline Multiple & $0.382(0.294-0.496)$ & $<0.001^{*}$ & $0.516(0.392-0.677)$ & $<0.001^{*}$ \\
\hline \multicolumn{5}{|l|}{ Degree of CAL } \\
\hline Only dilation & Reference & 1.00 & Reference & 1.00 \\
\hline Aneurysm & $0.246(0.158-0.382)$ & $<0.001^{*}$ & $0.319(0.202-0.505)$ & $<0.001^{*}$ \\
\hline \multicolumn{5}{|l|}{ Laboratory data } \\
\hline White blood cell count before IVIG & $0.979(0.962-0.997)$ & 0.019 & $1.004(0.981-1.020)$ & 0.971 \\
\hline Platelet count after IVIG & 0.999 (0.998-0.999) & 0.003 & $0.9992(0.9986-0.9998)$ & $0.007^{*}$ \\
\hline
\end{tabular}

Abbreviations: CAL coronary artery lesion; IVIG intravenous immunoglobulin; HR hazard ratio

Delayed IVIG was defined as the administration of IVIG $>10$ days after disease onset

Single CAL was defined as CAL in one of the following arteries: LMCA LAD, LCX, RCA, or PDCA. Multiple CAL was defined as CAL in more than one of these arteries

Dilation was defined as an absolute diameter of the coronary artery of $<4 \mathrm{~mm}$

Aneurysm was defined as an absolute diameter of the coronary artery of $\geq 4 \mathrm{~mm}$

We did not find a relationship between IVIG resistance and the duration of CALs. This may be due to repeated IVIG treatments or additional corticosteroid treatments in patients who did not initially respond to the treatment, resulting in a suppressed immune response and inflammation. Therefore, no difference in the immune function was observed between patients who received multiple rounds of IVIG or additional corticosteroid treatment and patients who received only one round of IVIG. We did not find any other significant associations between other clinical symptoms or laboratory data and the duration of CALs.

This study is not without limitations. First, because CAL was detected by echocardiography, both the occurrence and disappearance of CAL might show earlier than the check time point. According to previous research, the occurrence and the disappearance of CAL mostly happen in the subacute phase. Therefore, the follow-up strategy was made because the subacute-phase follow-up examination was more intensive than the chronic phase. We tried to make the duration of CAL obtained from the echocardiography closer to the real-time. Second, as this study began in 2010, we did not use the z-score to determine the degree of CALs, which has recently been reported as more appropriate [21, 29]. Instead, we used the previous standard measurement of absolute luminal diameter to assess the severity of CAL. This resulted in the aneurysm group being significantly older than the dilation group. Third, the data may have been biased as they were obtained from a clinical centre. Fourth, the follow-up period of 2 years was not long enough to determine the outcome of all patients with CAL.

\section{Conclusions}

In this retrospective study, the duration of CAL was longer in patients with KD with a greater degree of CAL, multiple CALs, higher platelet counts after IVIG, and delayed IVIG treatment. Therefore, these factors should be monitored carefully by paediatricians. Cardiac coronary artery examinations, including angiography and percutaneous coronary interventions, and anticoagulant therapies should be used in patients with KD.

\section{Abbreviations}

KD: Kawasaki disease; IVIG: Intravenous immunoglobulin; CAL: Coronary artery lesion; CAA: Coronary artery aneurysm; AHA: American heart association; LMCA: Left main coronary artery; LADA: Left anterior descending artery; LCX: Left circumflex; RCA: Right coronary artery; PDCA: Posterior descending coronary artery; LMP: Luminal myofibroblastic proliferation; Cl: Confidence interval; HR: Hazard ratio; M: Male; F: Female; LN: Lymph node 


\section{Acknowledgements}

Not applicable.

\section{Authors' contributions}

All authors have made substantial contributions to (1) the conception and design of the study, acquisition of data, or analysis and interpretation of data; (2) drafting the article or critically revising it for important intellectual content; and (3) final approval of the submitted version of the manuscript. All authors read and approved the final manuscript.

\section{Funding}

The work was supported by the Natural Science Foundation of China (No. 81970435), Zhejiang Provincial Science and Technology Project of Traditional Chinese Medicine (No. 2018ZZ019), and the Special Project for Significant New Drug Research and Development in the Major National Science and Technology Projects of China (No. 2020ZX09201002).

\section{Availability of data and materials}

The datasets generated during and analysed during the current study are not publicly available due to data protection but are available from the corresponding author on reasonable request.

\section{Declarations}

\section{Ethics approval and consent to participate}

The study was approved by the local ethics committee of The Second Affiliated Hospital and Yuying Children's Hospital, China. Written informed consent was waived due to the retrospective nature of the study.

\section{Consent for publication}

Not applicable.

\section{Competing interests}

The authors declare that they have no competing interests.

Received: 17 February 2021 Accepted: 8 April 2021

Published online: 26 June 2021

\section{References}

1. McCrindle BW, Rowley AH, Newburger JW, Burns JC, Bolger AF, Gewitz M, et al. Diagnosis, treatment, and long-term Management of Kawasaki Disease: a scientific statement for health professionals from the American Heart Association. Circulation. 2017;135:e927-e99.

2. Fukazawa R, Kobayashi J, Ayusawa M, Hamada H, Miura M, Mitani Y, et al. JCS/JSCS 2020 guideline on diagnosis and Management of Cardiovascular Sequelae in Kawasaki disease. Circ J. 2020;84(8):1348-407. https://doi.org/1 0.1253/circj.CJ-19-1094.

3. Xie LP, Yan WL, Huang M, Huang MR, Chen S, Huang GY, et al. Epidemiologic features of Kawasaki disease in Shanghai from 2013 through 2017. J Epidemiol. 2020;30(10):429-35. https://doi.org/10.2188/jea.JE201 90065.

4. Skochko SM, Jain S, Sun X, Sivilay N, Kanegaye JT, Pancheri J, et al. Kawasaki disease outcomes and response to therapy in a multiethnic community: a 10-year experience. J Pediatr. 2018;203:408-15 e3. https://doi.org/10.1016/j. jpeds.2018.07.090.

5. Ae R, Makino N, Kosami K, Kuwabara M, Matsubara Y, Nakamura Y. Epidemiology, treatments, and cardiac complications in patients with Kawasaki disease: the Nationwide survey in Japan, 2017-2018. J Pediatr. 2020;225:23-9 e2. https://doi.org/10.1016/j.jpeds.2020.05.034.

6. Fujino M, Hata T, Kuriki M, Horio K, Uchida H, Eryu Y, et al. Inflammation aggravates heterogeneity of ventricular repolarization in children with Kawasaki disease. Pediatr Cardiol. 2014;35(7):1268-72. https://doi.org/10.1 007/s00246-014-0926-2.

7. Miura M, Kobayashi T, Kaneko T, Ayusawa M, Fukazawa R, Fukushima N, et al. Association of Severity of coronary artery aneurysms in patients with Kawasaki disease and risk of later coronary events. JAMA Pediatr. 2018 172(5):e180030. https://doi.org/10.1001/jamapediatrics.2018.0030.

8. Orenstein JM, Shulman ST, Fox LM, Baker SC, Takahashi M, Bhatti TR, et al. Three linked vasculopathic processes characterize Kawasaki disease: a light and transmission electron microscopic study. PLoS One. 2012;7(6):e38998. https://doi.org/10.1371/journal.pone.0038998.
9. Daniels LB, Tjajadi MS, Walford HH, Jimenez-Fernandez S, Trofimenko V, Fick DB Jr, et al. Prevalence of Kawasaki disease in young adults with suspected myocardial ischemia. Circulation. 2012;125(20):2447-53. https://doi.org/10.11 61/CIRCULATIONAHA.111.082107.

10. Tang $Y$, Yan $W$, Sun $L, X u$ Q, Ding $Y, L v$ H. Coronary artery aneurysm regression after Kawasaki disease and associated risk factors: a 3-year followup study in East China. Clin Rheumatol. 2018;37(7):1945-51. https://doi.org/1 0.1007/s10067-018-3977-6.

11. Liu L, Luo C, Hua Y, Wu M, Shao S, Liu X, et al. Risk factors associated with progression and persistence of small- and medium-sized coronary artery aneurysms in Kawasaki disease: a prospective cohort study. Eur J Pediatr. 2020;179(6):891-900. https://doi.org/10.1007/s00431-019-03492-8.

12. Waki K, Arakaki Y, Mitsudo K. Long-term outcome of transcatheter polytetrafluoroethylene-covered stent implantation in a giant coronary aneurysm of a child with Kawasaki disease. Catheter Cardiovasc Interv. 2013; 81(4):713-6. https://doi.org/10.1002/ccd.24486.

13. Bang JS, Kim GB, Kwon BS, Song MK, An HS, Song YW, et al. Long-term prognosis for patients with Kawasaki disease complicated by large coronary aneurysm (diameter $>/=6$ mm). Korean Circ J. 2017;47(4):516-22. https://doi. org/10.4070/kcj.2016.0163.

14. McNeal-Davidson A, Fournier A, Scuccimarri R, Dancea A, Houde C, Bellavance $\mathrm{M}$, et al. The fate and observed management of giant coronary artery aneurysms secondary to Kawasaki disease in the province of Quebec: the complete series since 1976. Pediatr Cardiol. 2013;34(1):170-8. https://doi. org/10.1007/s00246-012-0409-2.

15. Son MBF, Gauvreau K, Tremoulet AH, Lo M, Baker AL, de Ferranti S, et al. Risk model development and validation for prediction of coronary artery aneurysms in Kawasaki disease in a north American population. J Am Heart Assoc. 2019;8:e011319.

16. Jeon SK, Kim G, Ko H, Byun JH, Lee HD. Risk factors for the occurrence and persistence of coronary aneurysms in Kawasaki disease. Korean J Pediatr. 2019;62(4):138-43. https://doi.org/10.3345/kjp.2018.07052

17. Ruan $Y$, Ye B, Zhao X. Clinical characteristics of Kawasaki syndrome and the risk factors for coronary artery lesions in China. Pediatr Infect Dis J. 2013; 32(10):e397-402. https://doi.org/10.1097/INF.0b013e31829dd45e.

18. Kuwabara M, Yashiro M, Kotani K, Tsuboi S, Ae R, Nakamura Y, et al. Cardiac lesions and initial laboratory data in Kawasaki disease: a nationwide survey in Japan. J Epidemiol. 2015;25(3):189-93. https://doi.org/10.2188/jea.JE2014 0128

19. Fu P, Du Z, Pan Y. Novel predictors of intravenous immunoglobulin resistance in Chinese children with Kawasaki disease. Pediatr Infect Dis J. 2013;32(8):e319-23. https://doi.org/10.1097/INF.0b013e31828e887f.

20. Wang Y, Wang W, Gong F, Fu S, Zhang Q, Hu J, et al. Evaluation of intravenous immunoglobulin resistance and coronary artery lesions in relation to Th1/Th2 cytokine profiles in patients with Kawasaki disease. Arthritis Rheum. 2013;65(3):805-14. https://doi.org/10.1002/art.37815.

21. Friedman KG, Gauvreau K, Hamaoka-Okamoto A, Tang A, Berry E, Tremoulet $\mathrm{AH}$, et al. Coronary artery aneurysms in Kawasaki disease: risk factors for progressive disease and adverse cardiac events in the US population. J Am Heart Assoc. 2016;5(9). https://doi.org/10.1161/JAHA.116.003289.

22. Chen PT, Lin MT, Chen YS, Chen SJ, Wu MH. Computed tomography predict regression of coronary artery aneurysm in patients with Kawasaki disease. J Formos Med Assoc. 2017;116(10):806-14. https://doi.org/10.1016/j.jma.2017. 07.001.

23. Egami $K$, Muta $H$, Ishii $M$, Suda $K$, Sugahara $Y$, lemura $M$, et al. Prediction of resistance to intravenous immunoglobulin treatment in patients with Kawasaki disease. J Pediatr. 2006;149(2):237-40. https://doi.org/10.1016/j. jpeds.2006.03.050.

24. Kobayashi T, Inoue Y, Takeuchi K, Okada Y, Tamura K, Tomomasa T, et al. Prediction of intravenous immunoglobulin unresponsiveness in patients with Kawasaki disease. Circulation. 2006;113(22):2606-12. https://doi.org/1 0.1161/CIRCULATIONAHA.105.592865.

25. Ae R, Abrams JY, Maddox RA, Schonberger LB, Nakamura Y, Shindo A, et al. Platelet count variation and risk for coronary artery abnormalities in Kawasaki disease. Pediatr Infect Dis J. 2020;39(3):197-203. https://doi.org/1 0.1097/INF.00000000000002563.

26. Arora K, Guleria S, Jindal AK, Rawat A, Singh S. Platelets in Kawasaki disease: is this only a numbers game or something beyond? Genes Dis. 2020;7(1): 62-6. https://doi.org/10.1016/j.gendis.2019.09.003.

27. Qiu H, He Y, Rong X, Ren Y, Pan L, Chu M, et al. Delayed intravenous immunoglobulin treatment increased the risk of coronary artery lesions in 
children with Kawasaki disease at different status. Postgrad Med. 2018; 130(4):442-7. https://doi.org/10.1080/00325481.2018.1468712.

28. Muta H, Ishii M, Yashiro M, Uehara R, Nakamura Y. Late intravenous immunoglobulin treatment in patients with Kawasaki disease. Pediatrics. 2012;129(2):e291-7. https://doi.org/10.1542/peds.2011-1704.

29. Son MBF, Gauvreau K, Kim S, Tang A, Dedeoglu F, Fulton DR, et al. Predicting coronary artery aneurysms in Kawasaki disease at a north American center: An assessment of baseline z scores. J Am Heart Assoc. 2017;6(6). https://doi.org/10.1161/JAHA.116.005378.

\section{Publisher's Note}

Springer Nature remains neutral with regard to jurisdictional claims in published maps and institutional affiliations.

Ready to submit your research? Choose BMC and benefit from:

- fast, convenient online submission

- thorough peer review by experienced researchers in your field

- rapid publication on acceptance

- support for research data, including large and complex data types

- gold Open Access which fosters wider collaboration and increased citations

- maximum visibility for your research: over $100 \mathrm{M}$ website views per year

At BMC, research is always in progress.

Learn more biomedcentral.com/submissions 